\title{
Glycerol carbonate as green solvent for pretreatment of sugarcane bagasse
}

\author{
Zhanying Zhang ${ }^{1,2^{*}}$, Darryn W Rackemann², William O S Doherty ${ }^{2}$ and lan M O'Hara ${ }^{1,2}$
}

\begin{abstract}
Background: Pretreatment of lignocellulosic biomass is a prerequisite for effective saccharification to produce fermentable sugars. In this study, "green" solvent systems based on acidified mixtures of glycerol carbonate (GC) and glycerol were used to treat sugarcane bagasse and the roles of each solvent in deconstructing biomass were determined.

Results: Pretreatment of sugarcane bagasse at $90^{\circ} \mathrm{C}$ for only 30 min with acidified GC produced a solid residue having a glucan digestibility of $90 \%$ and a glucose yield of $80 \%$, which were significantly higher than a glucan digestibility of $16 \%$ and a glucose yield of 15\% obtained for bagasse pretreated with acidified ethylene carbonate (EC). Biomass compositional analyses showed that GC pretreatment removed more lignin than EC pretreatment (84\% vs 54\%). Scanning electron microscopy (SEM) showed that fluffy and size-reduced fibres were produced from GC pretreatment whereas EC pretreatment produced compact particles of reduced size. The maximal glucan digestibility and glucose yield of GC/glycerol systems were about 7\% lower than those of EC/ethylene glycol (EG) systems. Replacing up to 50 wt\% of GC with glycerol did not negatively affect glucan digestibility and glucose yield. The results from pretreatment of microcrystalline cellulose (MCC) showed that (1) pretreatment with acidified alkylene glycol (AG) alone increased enzymatic digestibility compared to pretreatments with acidified alkylene carbonate (AC) alone and acidified mixtures of $A C$ and $A G$, (2) pretreatment with acidified GC alone slightly increased, but with acidified EC alone significantly decreased, enzymatic digestibility compared to untreated MCC, and (3) there was a good positive linear correlation of enzymatic digestibility of treated and untreated MCC samples with congo red (CR) adsorption capacity.

Conclusions: Acidified GC alone was a more effective solvent for pretreatment of sugarcane bagasse than acidified EC alone. The higher glucose yield obtained with GC-pretreated bagasse is possibly due to the presence of one hydroxyl group in the GC molecular structure, resulting in more significant biomass delignification and defibrillation, though both solvent pretreatments reduced bagasse particles to a similar extent. The maximum glucan digestibility of GC/glycerol systems was less than that of EC/EG systems, which is likely attributed to glycerol being less effective than EG in biomass delignification and defibrillation. Acidified AC/AG solvent systems were more effective for pretreatment of lignin-containing biomass than MCC.
\end{abstract}

Keywords: Pretreatment, Glycerol carbonate, Ethylene carbonate, Sugarcane bagasse, Microcrystalline cellulose, Enzymatic hydrolysis, Adsorption

\section{Background}

Lignocellulosic biomass is the most abundant renewable resource on earth and has the potential to partly replace fossil-based resources for production of fuels and chemicals. Lignocellulosic biomass consists of three major

\footnotetext{
* Correspondence: jan.zhang@qut.edu.au

${ }^{1}$ Syngenta Centre for Sugarcane Biofuels Development, Queensland University of Technology, GPO Box 2432, 2 George St, Brisbane, QLD 4001 Australia

${ }^{2}$ Centre for Tropical Crops and Biocommodities, Queensland University of Technology, GPO Box 2432, 2 George St, Brisbane, QLD 4001, Australia
}

components, cellulose, hemicellulose and lignin with cellulose being embedded in a matrix of the latter two structural biopolymers. Pretreatment is essential to improve cellulose accessibility to cellulase enzymes for production of fermentable sugars $[1,2]$. However, the major obstacle to using lignocellulosic biomass is the high processing costs, which are mainly associated with pretreatment reactor capital costs and consumption of energy and chemicals used for pretreatment [1-3].

Pretreatment of lignocellulosic biomass at low temperatures of $\leq 100^{\circ} \mathrm{C}$ can save up to $50 \%$ energy consumption

\section{Biomed Central}


compared to alternative pretreatments (e.g., dilute acid pretreatments with water as solvent) operated at temperatures of $160-180^{\circ} \mathrm{C}$ [3]. While water is the most benign, environmentally friendly and importantly cheap solvent, it provides limited impact on biomass deconstruction under mild pretreatment temperatures of $\leq 100^{\circ} \mathrm{C}$ unless used in conjunction with concentrated mineral acids $[4,5]$. However, the use of large amounts of acid introduce issues regarding reactor corrosion and acid recovery and requires the treatment of the acid residue, producing a lot of wastes [6].

Low temperature pretreatment processes with the use of high boiling point solvents such as some ionic liquids do not require high pressure reactors and reduce the rates of reactor corrosion allowing less expensive materials to be used for reactor construction (e.g., thinner reactor walls and lower priced alloys). A few imidazolium ionic liquid-based pretreatments have been used to achieve glucan digestibilities of $\geq 90 \%$ for lignocellulosics pretreated at temperatures of $\leq 130^{\circ} \mathrm{C}[7,8]$. However, the high solvent costs of these ionic liquids could hamper their applications at industrial scales. Recently, pretreatment of rice straw with low cost and renewable chlolinium amino acid ionic liquid-water mixtures at a temperature of $90^{\circ} \mathrm{C}$ have also been reported [9]. However, this pretreatment requires a reaction time of $12 \mathrm{~h}$ to achieve sugar yields of $>80 \%$.

We have previously reported a low temperature $\left(90^{\circ} \mathrm{C}\right)$ process for atmospheric pretreatment of sugarcane bagasse with mixtures of ethylene carbonate (EC) and ethylene glycol (EG), which are industrially available, low cost solvents [10]. The EC/EG-based pretreatment produces biomass having a maximal glucan enzymatic digestibility of $93 \%$, making it very effective. The high effectiveness of the EC/EG-based systems is attributed to (1) EC's ability to reduce particle size (length) due to its high static relative dielectric constant $(\varepsilon)$, (2) EG's ability to defibrillate biomass and (3) both solvents' ability to remove lignin from biomass under acidified conditions. Although EC itself is considered a solvent of low toxicity [11], its decomposition product, EG (also used in the pretreatment system) is toxic to human health. Long term exposure to EG may cause metabolic acidosis, cardiopulmonary failure and acute renal failure [12]. We are therefore interested in other cyclic carbonates, which have similar or higher $\varepsilon$ values but are "greener" and less toxic than EC.

Glycerol carbonate (GC) is such a cyclic alkylene carbonate $(\mathrm{AC})$. GC has a similar structure to propylene carbonate $(\mathrm{PC})$ (with one hydrogen from the methyl group in $\mathrm{PC}$ replaced by a hydroxyl group) (Figure 1) and has the highest $\varepsilon$ value among these three cyclic carbonates [13]. GC is classified as a low toxicity, sustainable solvent and is a promising versatile building block chemical with

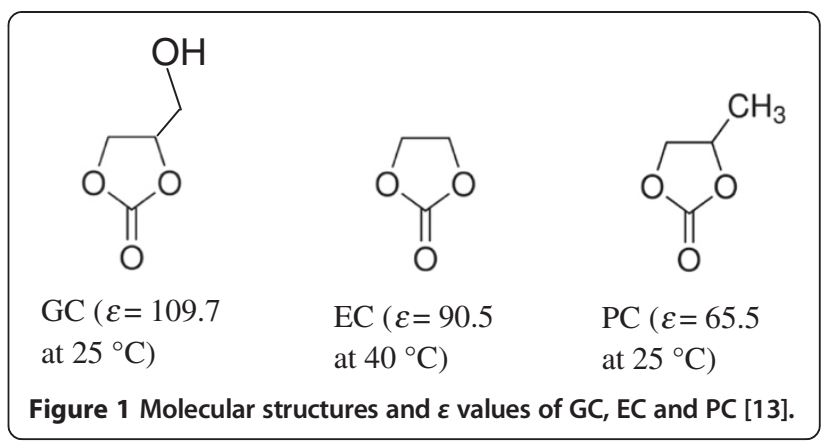

numerous applications [11]. Both GC and its decomposition product glycerol show very low toxicities [11]. Interestingly, $\mathrm{GC}$ can be synthesized by reaction of $\mathrm{CO}_{2}$ $[14,15]$, urea [16,17] and dialkyl carbonates [18-22] with glycerol in the presence of chemical or enzymatic catalysts. In particular, glycerol is produced in large quantities in the biodiesel industry, making it readily available and cheap. GC synthesis is being suggested as a way to valorize glycerol from the biodiesel process [11]. Furthermore, GC has a boiling point of $354^{\circ} \mathrm{C}$, much higher than that of EC $\left(260^{\circ} \mathrm{C}\right)$. Its decomposition product glycerol has a boiling point of $290^{\circ} \mathrm{C}$, which is much higher than EC's decomposition product EG $\left(197^{\circ} \mathrm{C}\right)$. The higher boiling points of GC and glycerol make them more suitable for atmospheric reaction than the EC/EG systems.

We also hypothesized that the presence of one hydroxyl group in GC's molecular structure may enhance biomass swelling and defibrillation as occurs with alkylene glycols (AGs). We herein investigated the effectiveness of GC/glycerol systems to deconstruct sugarcane bagasse for enzymatic saccharification in comparison to the EC/EG systems. Furthermore, both GC/glycerol and $\mathrm{EC} / \mathrm{EG}$ systems were used to pretreat microcrystalline cellulose (MCC) such that the effect of the solvent solely on cellulose could be examined. Enzymatic digestion of and congo red (CR) adsorption on MCC pretreated with these solvent systems were analysed and compared to better understand the roles of the individual solvents in pretreatment.

\section{Results and discussion}

\section{Pretreatment of sugarcane bagasse}

\section{Biomass composition and component recovery}

Pretreatments were conducted with AC/AG solvents containing $1.2 \% \mathrm{H}_{2} \mathrm{SO}_{4}$. With this acid concentration, pretreatment by EC/EG was most effective at $90^{\circ} \mathrm{C}$ for $30 \mathrm{~min}$ in terms of delignification, xylan removal and glucan digestibility [10]. Table 1 shows the results of biomass composition and component recovery. All the GC/glycerol pretreatments improved glucan content in biomass but decreased xylan and lignin contents. Decreasing GC content in the solvent decreased glucan 
Table 1 Biomass composition, component recovery, glucan digestibility and glucose yield of pretreated bagasse

\begin{tabular}{|c|c|c|c|c|c|c|c|c|c|c|}
\hline \multirow{2}{*}{$\begin{array}{c}\text { Solvent } \\
\text { type }\end{array}$} & \multirow{2}{*}{$\begin{array}{l}\text { AC: } \\
\text { AG }\end{array}$} & \multicolumn{3}{|c|}{ Content in solid residue (wt\%) } & \multicolumn{4}{|c|}{ Component recovery (\%) } & \multirow{2}{*}{$\begin{array}{c}72 \mathrm{~h} \text { glucan } \\
\text { digestibility (\%) }\end{array}$} & \multirow{2}{*}{$\begin{array}{c}\text { Total glucose } \\
\text { yield (\%) }\end{array}$} \\
\hline & & Glucan & Xylan & Lignin & Biomass & Glucan & Xylan & Lignin & & \\
\hline \multicolumn{2}{|c|}{ Untreated bagasse } & $43.8 \pm 1.3$ & $20.2 \pm 0.4$ & $27.5 \pm 0.6$ & 100.0 & 100.0 & 100.0 & 100.0 & $12.0 \pm 0.3$ & $12.0 \pm 0.3$ \\
\hline \multirow[t]{6}{*}{ GC:glycerol } & $1: 0$ & $75.6 \pm 0.7$ & $7.6 \pm 0.1$ & $8.6 \pm 0.2$ & $51.9 \pm 1.8$ & $89.6 \pm 1.0$ & $19.5 \pm 0.5$ & $16.3 \pm 0.6$ & $89.9 \pm 1.7$ & $80.5 \pm 2.1$ \\
\hline & $9: 1$ & $74.8 \pm 0.2$ & $9.9 \pm 0.0$ & $9.7 \pm 0.4$ & $53.9 \pm 0.8$ & $92.0 \pm 1.0$ & $26.3 \pm 0.7$ & $19.0 \pm 0.7$ & $90.2 \pm 2.2$ & $83.0 \pm 3.3$ \\
\hline & $4: 1$ & $74.9 \pm 0.1$ & $10.2 \pm 0.0$ & $9.1 \pm 0.2$ & $55.6 \pm 1.6$ & $95.1 \pm 1.1$ & $28.0 \pm 0.6$ & $18.4 \pm 0.4$ & $87.1 \pm 2.1$ & $82.9 \pm 0.9$ \\
\hline & $2: 1$ & $72.0 \pm 0.4$ & $11.9 \pm 0.1$ & $11.3 \pm 0.1$ & $57.6 \pm 2.3$ & $94.7 \pm 2.7$ & $34.0 \pm 0.2$ & $23.7 \pm 0.9$ & $86.9 \pm 1.8$ & $82.3 \pm 1.2$ \\
\hline & $1: 1$ & $68.7 \pm 0.2$ & $12.3 \pm 0.0$ & $12.0 \pm 0.1$ & $59.5 \pm 1.0$ & $93.3 \pm 1.4$ & $36.3 \pm 0.8$ & $25.9 \pm 0.3$ & $87.6 \pm 1.7$ & $81.7 \pm 1.8$ \\
\hline & $0: 1$ & $56.6 \pm 0.0$ & $13.8 \pm 0.0$ & $23.4 \pm 0.0$ & $73.6 \pm 1.9$ & $95.1 \pm 0.6$ & $50.3 \pm 0.8$ & $62.5 \pm 0.5$ & $61.3 \pm 2.2$ & $58.3 \pm 2.2$ \\
\hline \multirow[t]{3}{*}{ EC:EG } & $1: 0$ & $64.2 \pm 1.2$ & $7.0 \pm 0.1$ & $20.4 \pm 0.5$ & $61.8 \pm 2.5$ & $90.6 \pm 0.6$ & $21.3 \pm 0.4$ & $45.8 \pm 1.2$ & $16.3 \pm 1.3$ & $14.8 \pm 1.6$ \\
\hline & $4: 1$ & $76.7 \pm 0.3$ & $10.1 \pm 0.0$ & $7.5 \pm 0.3$ & $53.1 \pm 0.5$ & $93.0 \pm 1.2$ & $26.5 \pm 0.3$ & $14.4 \pm 0.3$ & $97.1 \pm 1.8$ & $90.3 \pm 2.1$ \\
\hline & $0: 1$ & $67.2 \pm 0.8$ & $14.1 \pm 0.2$ & $13.4 \pm 0.3$ & $62.4 \pm 0.9$ & $95.7 \pm 0.8$ & $43.6 \pm 1.1$ & $30.6 \pm 1.0$ & $74.7 \pm 2.8$ & $71.5 \pm 1.2$ \\
\hline
\end{tabular}

content but increased xylan and lignin contents. The highest glucan content (75.6 wt\%) in biomass was achieved with pretreatment by GC alone which also resulted in the lowest xylan (7.6 wt\%) and lignin (8.6 wt\%) contents. The biomass yield (recovery) decreased with decreasing glycerol content because of increased removal of xylan and lignin. Glucan recovery remained high ( $\geq 90 \%)$ at all GC:glycerol ratios.

Compared to $\mathrm{GC} /$ glycerol pretreatments, pretreatment by EC alone removed significantly less lignin but slightly more xylan. As a result, glucan content after EC pretreatment was $\sim 11 \%$ lower than that after GC pretreatment. Both EC and GC pretreatments led to lower glucan recoveries compared to the pretreatments with mixed carbonate and glycol solvents. This was likely attributed to the high solution acidity (due to the high solvent dielectric constants), which resulted in hydrolysis of more cellulose components. In the previous study, it was found that the optimal ratio of EC:EG for EC/EG systems was 4:1 [10]. At this ratio, EC/EG pretreatment led to slightly higher delignification than pretreatments by $\mathrm{GC} /$ glycerol systems with GC:glycerol ratios from 1:0 to 4:1. EG pretreatment removed more lignin than glycerol pretreatment possibly due to EG's high lignin solubility [23].

\section{Biomass characterisation}

Samples were also characterised using Fourier transform infrared spectroscopy (FTIR), X-ray powder diffraction (XRD) and scanning electron microscopy (SEM). Figure 2 shows the FTIR spectra of biomass samples. The intensities of lignin-associated peaks at $\sim 1732 \mathrm{~cm}^{-1}$ (related to the uronic acid ester bonds formed between the carboxylic acid group in hemicellulose and the phenolic hydroxyl group in lignin, and/or between the carboxylic acid group from lignin hydroxycinnamic acid and the hydroxyl group from arabinofuranose unit [24,25]), at $1605 \mathrm{~cm}^{-1}$ and 1515 $\mathrm{cm}^{-1}$ (assigned to aromatic skeleton vibrations in lignin [26]), at $1460 \mathrm{~cm}^{-1}$ (possibly associated with the methoxy group in lignin [27]), at $1240 \mathrm{~cm}^{-1}$ (assigned to $\beta$-ether bonds in lignin [26]) and at $835 \mathrm{~cm}^{-1}$ (which belongs to a $\mathrm{C}-\mathrm{H}$ out of plane vibration in lignin [28]) diminished or disappeared with bagasse pretreated with GC solutions (Figure 2). Some of these peaks associated with lignin were also weaker for bagasse pretreated with GC compared to bagasse pretreated with EC, and so explain the difference in biomass yield. The results imply that, under similar conditions, GC provides a better delignification capacity than EC.

The region of $1200-1000 \mathrm{~cm}^{-1}$ represents C-O stretch and deformation bands in cellulose, lignin and residual hemicellulose [29]. The increase in band intensity at $1200 \mathrm{~cm}^{-1}$ of pretreated bagasse may be related to the increase in the proportion of the glucan content. The band intensity at $1105 \mathrm{~cm}^{-1}$, which corresponds to crystalline cellulose [30] increased in all the pretreated bagasse samples compared to the untreated bagasse, indicating that the pretreatment removed amorphous components in the bagasse. XRD analysis also showed that the

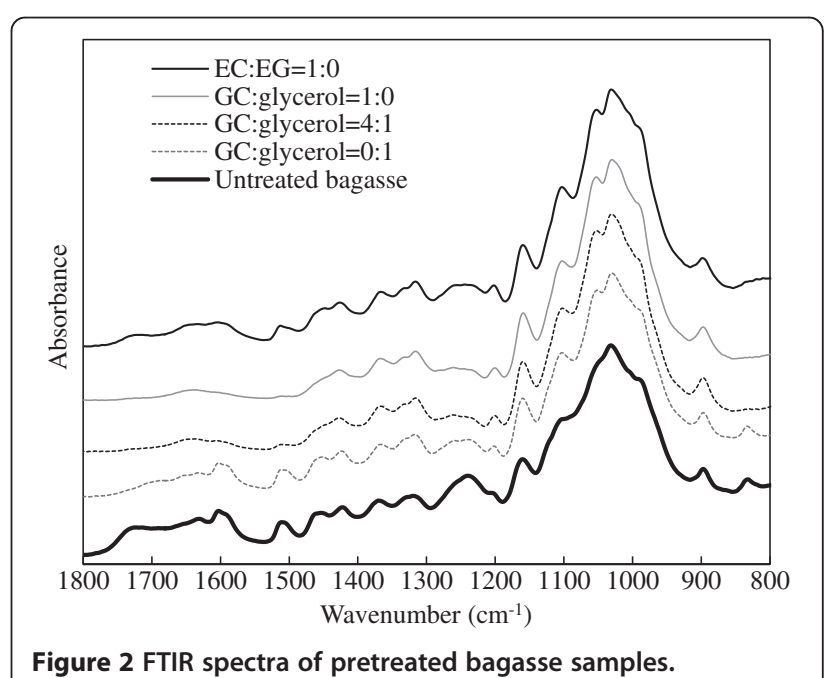


pretreatments did not decrease cellulose crystallinity (Additional file 1: Figure S1) and the estimated CrIs of the pretreated biomass $(0.73-0.75)$ were slightly higher than that of untreated bagasse (0.68). Slight increase in CrI was also observed in our previous studies where acidified solvents were used to pretreat sugarcane bagasse due to the removal of amorphous components $[10,31]$. Figure 2 also shows that the peak at $1050 \mathrm{~cm}^{-1}$, which is associated with the $\mathrm{C}-\mathrm{O}$ stretch in cellulose and hemicellulose [28], was prominent in pretreated bagasse, indicating the increase in glucan content. The peak at $898 \mathrm{~cm}^{-1}$ is characteristic of $\beta$-glycosidic linkages between the sugar units in carbohydrates [26].

As shown by the scanning electron microscopy (SEM) images, the average particle width of untreated bagasse was $\sim 250-500 \mu \mathrm{m}$ while after GC pretreatment the width was reduced to $\sim 40-150 \mu \mathrm{m}$ (Additional file 2: Figure S2a), similar to, if not smaller, than the particle width range of fibres from EC pretreatment (Additional file 2: Figure S2b). The fibres from GC pretreatment seem fluffy compared to the compact nature of the fibres obtained EC pretreatment (Additional file 2: Figures S2a and S2b). So defibrillation as well as size reduction occurred with GC pretreatment. Pretreatment by glycerol reduced biomass particle width to $60-120 \mu \mathrm{m}$ (Additional file 2: Figure S2c) while pretreatment by EG partially defibrillated biomass fibres (with a width range of $20-$ $30 \mu \mathrm{m}$ ) (Additional file 2: Figure S2d).

\section{Enzymatic hydrolysis of pretreated bagasse}

Table 1 also shows the glucan digestibility and glucose yield obtained from saccharification experiments. It is worth mentioning that without acid catalyst, AC/AG pretreatments had little effect on glucan digestibility of pretreated bagasse (data not shown). After $72 \mathrm{~h}$ enzymatic hydrolysis, cellobiose was not detected. Pretreatment with mixtures of GC/glycerol led to glucan digestibilities of $87-90 \%$ and glucose yields of $82-83 \%, \sim 25 \%$ higher than those with glycerol alone. The glucan digestibility and glucose yield obtained with GC pretreatment alone were $90 \%$ and $80 \%$ respectively, only slightly lower than that with mixtures of GC/glycerol. In comparison, our previous results showed that water-based pretreatment with $1.2 \mathrm{wt} \% \mathrm{HCl}$ as catalyst (which has higher acidity than $1.2 \mathrm{wt} \% \mathrm{H}_{2} \mathrm{SO}_{4}$ used in this study) in a sealed vessel at $130^{\circ} \mathrm{C}$ for $60 \mathrm{~min}$ only led to a glucan digestibility of only $38 \%$ [31].

These results from GC/glycerol pretreatments are significantly different from those results from EC/EG pretreatments. As previously reported the glucan digestibility and glucose yield of bagasse pretreated with the mixture of EC/EG was much higher than bagasse pretreated with $\mathrm{EC}$ alone and also significantly higher than bagasse pretreated with EG alone [10]. Repeated experiments with
EC/EG solvents in this study confirmed our previous observation (Table 1). Pretreatment with EC alone led to a glucan digestibility of $\sim 16 \%$ and a glucose yield of $\sim 15 \%$, which were significantly lower than those with pretreatment by GC alone. The higher glucose yield achieved with GC pretreatment may be attributed to GC's better delignification (Table 1) and defibrillation abilities (fluffy biomass generated from GC pretreatment as shown in Additional file 2: Figure S2a and S2b). As fluffy particles have larger specific surface area than compact particles, the accessibility of cellulose to cellulases is improved [32-34]. It was also noted that the pretreatment effectiveness using mixtures of GC/glycerol was slightly lower than the effectiveness using mixtures of EC/EG. This is attributed to the better biomass defibrillation and delignification [35] capacity of EG compared to glycerol. When glycerol in the GC/glycerol system was replaced by EG, a glucose yield of $\sim 90 \%$ was achieved, which was comparable to that of bagasse pretreated by EC/EG (data not shown).

The difference in pretreatment effectiveness between GC and EC is likely attributed to differences in their molecular structures (Figure 1). The presence of one hydroxyl group in an organic solvent enhances GC's capacity to delignify biomass similar to typical alcohol and phenol solvents [36-39] explaining why GC is a better biomass delignification and defibrillation solvent than EC. In addition, $\varepsilon$ of GC $\left(109.7\right.$ at $\left.25^{\circ} \mathrm{C}\right)$ is higher than that of EC $\left(90.5,40^{\circ} \mathrm{C}\right)$ [13]. For an acid-catalysed reaction in non-aqueous solvent, the acid potential is associated with the $\varepsilon$ of the solvent [40]. It is generally considered that a solvent with higher $\varepsilon$ also has a higher acid potential accounting for the similar (if not smaller) biomass particle size produced by GC compared to EC pretreatment.

\section{Pretreatment solution}

Glucose and 5-hydroxymethylfurfural (HMF, a glucose degradation product) which are generated in many acidcatalysed lignocellulose pretreatment processes, were not detected in any of the pretreatment solutions. The yields of xylose and furfural (a xylose degradation product) were very low (Table 2). The low yields of xylan derivatives may be attributed to the production of xylan oligomers $[41,42]$ and/or the formation of glycol-glycosides (glycol-glucosides and glycol-xylosides) [10,43]. Previous studies have shown that glycol-glycosides existed in the solutions collected after pretreatment using acidified glycols [43]. Glycol-glycosides were hydrolysed to glycol and sugars upon dilution and hydrolysis of the pretreatment solution [10,43]. In this study, formation of glycosides with glycerol was also likely because of the presence of glycerol. As shown in Table 2, the xylose yield increased significantly after hydrolysis of the pretreatment solutions. Also, 
Table 2 Component yield before and after hydrolysis of pretreatment solution

\begin{tabular}{|c|c|c|c|c|c|c|}
\hline \multirow[t]{2}{*}{ Solvent type } & \multirow[t]{2}{*}{ AC:AG } & \multicolumn{2}{|c|}{ Pretreatment solution } & \multicolumn{3}{|c|}{ Hydrolysed pretreatment solution ${ }^{1}$} \\
\hline & & Xylose (\%) & Furfural (\%) & Glucose (\%) & Xylose (\%) & Furfural (\%) \\
\hline \multirow[t]{6}{*}{ GC:glycerol } & $1: 0$ & $8.4 \pm 1.7$ & $0.3 \pm 0.0$ & $4.2 \pm 0.3$ & $73.2 \pm 2.5$ & $1.9 \pm 0.3$ \\
\hline & $9: 1$ & $6.8 \pm 0.4$ & $0.2 \pm 0.0$ & $2.8 \pm 0.3$ & $71.3 \pm 3.5$ & $2.1 \pm 0.3$ \\
\hline & $4: 1$ & $5.1 \pm 0.6$ & $0.2 \pm 0.1$ & $2.4 \pm 0.2$ & $67.1 \pm 5.1$ & $2.0 \pm 0.2$ \\
\hline & $2: 1$ & $4.4 \pm 0.1$ & $0.1 \pm 0.1$ & $2.0 \pm 0.1$ & $57.1 \pm 2.7$ & $1.0 \pm 0.2$ \\
\hline & $1: 1$ & $4.0 \pm 0.1$ & - & $1.5 \pm 0.1$ & $53.0 \pm 5.8$ & $0.5 \pm 0.1$ \\
\hline & $0: 1$ & $1.5 \pm 0.7$ & - & $0.6 \pm 0.2$ & $30.7 \pm 4.0$ & $0.3 \pm 0.0$ \\
\hline \multirow[t]{3}{*}{$\mathrm{EC}: \mathrm{EG}$} & $1: 0$ & $2.6 \pm 0.5$ & $9.5 \pm 0.5$ & $3.1 \pm 0.2$ & $38.8 \pm 3.7$ & $11.7 \pm 0.8$ \\
\hline & $4: 1$ & $2.9 \pm 0.4$ & $0.4 \pm 0.2$ & $1.8 \pm 0.5$ & $66.8 \pm 8.0$ & $1.2 \pm 0.2$ \\
\hline & $0: 1$ & $1.5 \pm 0.3$ & - & $0.5 \pm 0.1$ & $31.6 \pm 5.7$ & $0.6 \pm 0.1$ \\
\hline
\end{tabular}

1. Solvent solution collected after pretreatment was diluted to a water content of $75 \mathrm{wt} \%$ and hydrolysed in a sealed pressure tube for $30 \mathrm{~min}$ at $130^{\circ} \mathrm{C}$.

small amounts of glucose were present in the hydrolysed pretreatment solution. The xylose yield decreased with decreasing GC content possibly due to less xylan removed from bagasse (Table 1) and the inhibition of hydrolysis of glycerol-xylosides at higher glycerol concentrations. The same trend was observed with glucose yield. For EC/EG systems, the xylose yield in the hydrolysed pretreatment solution from EC pretreatment was lower than that in the solution from EC/EG pretreatments possibly because of the production of furfural (Table 2) and the formation of undetected xylose and furfural polymerisation or degradation products such as humins [44].

Similar to the EC/EG system [10], pretreatment by $\mathrm{GC} /$ glycerol was also accompanied by the gradual decomposition of GC to glycerol. For GC pretreatment, 6 wt $\%$ of GC was converted to glycerol after pretreatment at $90^{\circ} \mathrm{C}$ for $30 \mathrm{~min}$ (data not shown), which was slightly higher than that of EC conversion to EG ( $3 \mathrm{wt} \%)$ under similar conditions [10]. Nevertheless, ACs are very stable at neutral $\mathrm{pH}$. Therefore, after pretreatment the solvent solution can be neutralised and further processed to remove impurities (lignin with large molecular weights may be precipitated by adding water into the solution [18]; lignin with small molecular weights may be removed by adsorption with activated carbon [45]; soluble sugar-related products may be separated by chromatography techniques) and water (e.g., by vacuum evaporation). The kinematic viscosity (centistokes) of GC $\left(61\right.$ at $\left.25^{\circ} \mathrm{C}\right)$ is much lower than that of glycerol $\left(714\right.$ at $25^{\circ} \mathrm{C}$ ) although it is significantly higher than water $\left(0.9\right.$ at $\left.25^{\circ} \mathrm{C}\right)$ [46,47], indicating that $\mathrm{GC}$ process is more readily amenable than glycerol process to pretreatments at high biomass loadings, to separation of pretreated biomass and to recovery of solvent.

\section{Pretreatment of MCC \\ Cellulose yield and enzymatic hydrolysis}

To better understand the mechanism of pretreatment with AC/AG systems, MCC was also pretreated with GC/ glycerol and EC/EG systems and the substrates were hydrolysed by cellulases. As shown in Table 3, the cellulose yields after pretreatment of MCC by either GC/glycerol or EC/EG systems were $87-93 \%$, close to the glucan recoveries of pretreated bagasse, confirming that AC/AG systems does not hydrolyse glucan significantly under the present reaction conditions. The lowest cellulose yield was achieved with pretreatment with $\mathrm{AC}$ alone whereas the highest cellulose yield was obtained with

Table 3 Cellulose yield, glucan digestibility and glucose yield of pretreated MCC

\begin{tabular}{ccccc}
\hline Solvent type & AC:AG & Cellulose yield (\%) & 72 h glucan digestibility (\%) & Total glucose yield (\%) \\
\hline GC:glycerol & $1: 0$ & $87.0 \pm 1.4$ & $76.0 \pm 2.9$ & $66.1 \pm 2.5$ \\
& $4: 1$ & $91.4 \pm 3.6$ & $75.3 \pm 2.7$ & $68.8 \pm 2.5$ \\
& $0: 1$ & $93.0 \pm 0.9$ & $83.2 \pm 1.3$ & $77.4 \pm 1.2$ \\
EC:EG & $1: 0$ & $89.2 \pm 2.1$ & $60.1 \pm 2.0$ & $53.6 \pm 1.8$ \\
& $4: 1$ & $91.1 \pm 2.6$ & $74.1 \pm 1.3$ & $67.5 \pm 1.2$ \\
& $0: 1$ & $92.9 \pm 2.6$ & $81.0 \pm 0.6$ & $75.3 \pm 0.6$ \\
Untreated MCC & & 100.0 & $72.2 \pm 0.5$ & $72.2 \pm 0.5$ \\
\hline
\end{tabular}


AG alone, although the difference was not significant. In addition, the highest amounts of glucose were detected in the hydrolysed pretreatment solutions with ACs (Additional file 3: Figure S3). These data indicated that AC pretreatment increased depolymerisation of cellulose.

Table 3 also shows the glucose yield and glucan digestibility of pretreated MCC after $72 \mathrm{~h}$ enzymatic hydrolysis. MCC pretreated by EC alone had the lowest glucan digestibility of only $60.0 \%$, lower than that of untreated MCC (72.2\%) and also much lower than that of MCC pretreated by GC alone (76.0\%). Residual solvents were not detected in the washed biomass by HPLC analysis (data not shown), indicating the enzymatic hydrolysis of pretreated bagasse were not inhibited by the solvents. Pretreatment with EC/EG mixture (4:1) led to an increase in glucan digestibility by $14 \%$ compared to that with EC pretreatment. However, there was no obvious difference between the glucan digestibilities of MCC pretreated by GC alone and the mixture of GC/glycerol. MCC pretreated by glycerol and EG had the highest glucan digestibilities. This may be attributed to the better deconstruction of MCC by polyols. SEM images show that the particle width range of untreated MCC was $\sim 25-60 \mu \mathrm{m}$ (Additional file 4: Figure S4a). After pretreatment, the particle width range was reduced. The particle width range was $\sim 12-30 \mu \mathrm{m}$ for MCC pretreated by GC alone (Additional file 4: Figure S4c) and is similar to the particle width range for MCC pretreated by EC or glycerol alone (Additional file 4: Figures S4b and S4e). The average particle width $(\sim 18-$ $40 \mu \mathrm{m})$ of MCC pretreated by EG alone was slightly higher than other pretreated MCC (Additional file 4: Figure S4d). However, the MCC pretreated by EG alone seemed fluffy (i.e., defibrillated) compared to that pretreated by EC alone. Total glucose yield followed a similar trend to glucan digestibility as the cellulose yield only changed slightly among pretreatments.

\section{Correlation of glucan digestibility with $C R$ adsorption}

The effect of pretreatment on biomass surface area was evaluated by dye adsorption tests. CR adsorption on MCC matched Langmuir isotherm (Additional file 5: Figure S5), indicating there is a positive linear relationship between dye adsorption capacity and the biomass surface area [48]. As shown in Figure 3, MCC pretreated by $\mathrm{EC}$ alone had the lowest $\mathrm{CR}$ adsorption capacity while glycerol- and EG-pretreated MCC had the highest $\mathrm{CR}$ adsorption capacities. The high adsorption capacity of MCC pretreated by acidified EG was likely attributed to its ability to swell cellulose [49] and thus produced fluffy biomass. Although MCC pretreated with glycerol was not as fluffy as EG-pretreated MCC, pretreatment by glycerol possibly produced porous biomass [35], which also increased the biomass surface area for CR adsorption.

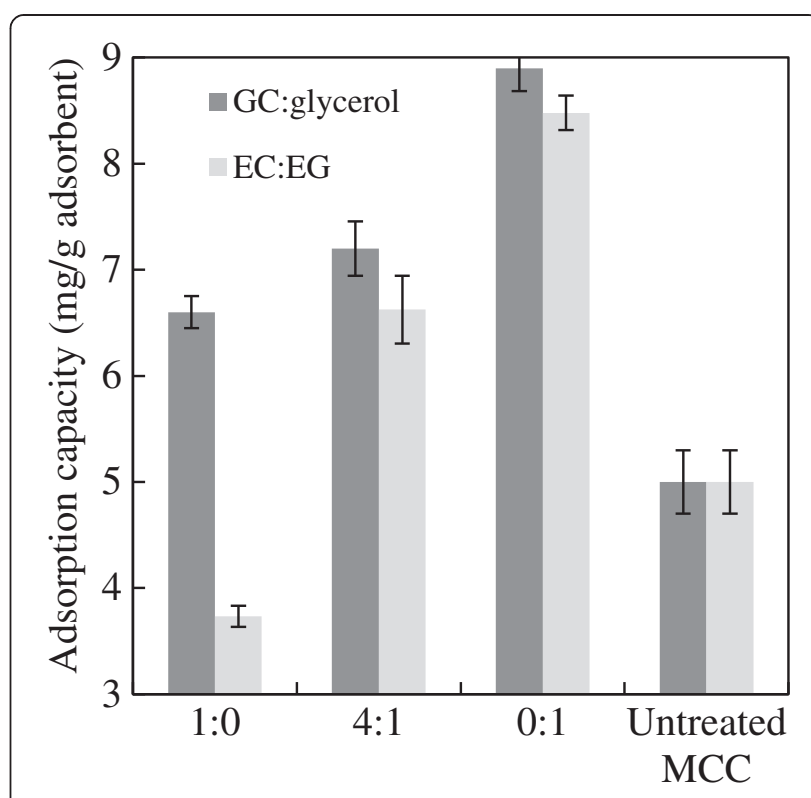

Figure 3 CR adsorption capacity of pretreated MCC.

A good linear correlation $\left(R^{2}=0.9063\right)$ of glucan digestibility with $\mathrm{CR}$ adsorption capacity was observed for the pretreated MCC (Figure 4).

\section{Conclusions}

Pretreatment of sugarcane bagasse with acidified GC alone was much more effective that the pretreatment with acidified EC alone. Up to $50 \mathrm{wt} \%$ of GC could be replaced by glycerol without having a negative effect on the pretreatment effectiveness. The maximum glucan digestibility of $\mathrm{GC} /$ glycerol systems was less than that

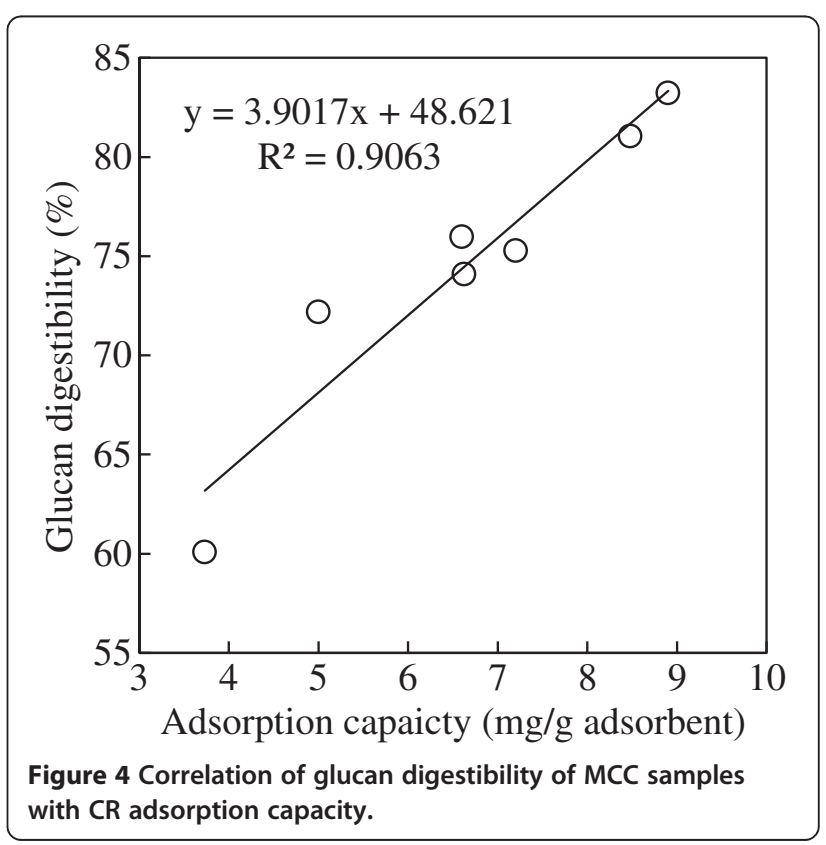


of EC/EG systems, which is likely attributed to glycerol being less effective than EG in biomass delignification and defibrillation. The results also showed that AC/AG solvent systems were more effective for pretreatment of lignin-containing biomass than MCC.

Although GC and EC are considered non-toxic to human health, EG is much more toxic than glycerol. From the aspect of operational safety, GC/glycerol systems may be preferred over EC/EG systems. Currently, the price of GC is high as it is not produced commercially. Development of technology for GC synthesis based on the low cost glycerol and $\mathrm{CO}_{2}$ feedstocks may decrease $\mathrm{GC}$ production cost and make the use of GC for processing biomass more competitive.

\section{Methods \\ Materials}

Sugarcane bagasse was collected from Racecourse Sugar Mill (Mackay Sugar Limited) in Mackay, Australia. Sugarcane bagasse was washed with hot water at $90^{\circ} \mathrm{C}$ to remove residual sugars to a negligible amount. The washed sugarcane bagasse was air-dried, and gently shaked on a sieve having an aperture size of $1.0 \mathrm{~cm}$ to remove pith and the residues were ground to fine particles by a cutter grinder (Retsch ${ }^{\odot}$ SM100, Retsch GmBH, Germany). The milled bagasse was screened and particles having width range of $250-500 \mu \mathrm{m}$ were collected and stored for pretreatment. The moisture of the sieved bagasse particles was $7.1 \mathrm{wt} \%$. Bagasse particles mainly consisted of 43.8 wt\% glucan, $20.2 \mathrm{wt} \%$ xylan, $3.3 \mathrm{wt} \%$ arabinan, $27.5 \mathrm{wt} \%$ lignin, $2.5 \mathrm{wt} \%$ acetyl and $2.1 \mathrm{wt} \%$ ash. GC, glycerol, EC, EG, MCC (Avicel ${ }^{\odot} \mathrm{PH}-101$ ) and CR were purchased from Sigma-Aldrich (US). Accellerase ${ }^{\mathrm{Ts}} 1000$ (Batch no. 1600877126), a Danisco product (Genencor Division, Danisco Inc., US), was purchased through Enzymes Solutions Pty. Ltd (Australia). Accellerase ${ }^{\mathrm{TM}} 1000$ contained $30.4 \mathrm{mg}$ protein $/ \mathrm{mL}$ enzyme solution, which was measured using Bradford Protein Assay Kit purchased from Bio-Rad (US). The filter paper activity of Accellerase $^{\mathrm{Tm}} 1000$ was $40 \mathrm{FPU} / \mathrm{mL}$, which was measured using a method developed by the National Renewable Energy Laboratory (NREL, US) [50]. All the chemicals used in this study were analytic standard reagents.

\section{Pretreatment experiment}

The pretreatment solvent $(4.90 \mathrm{~g})$ was transferred into a $60 \mathrm{~mL}$ pressure tube $(10.2 \mathrm{~cm}$ (length) $\times 3.81 \mathrm{~cm}$ (diameter), Ace Glass Inc., USA) which was immersed in a silicone oil bath preheated to $95^{\circ} \mathrm{C}$. The pressure tube was not sealed and pretreatment was conducted at atmospheric pressure. The heating element was equipped with a magnetic stirring device with a stirring speed of $300 \mathrm{rpm}$ (Ika Labortechnik, Germany). A picture of this pretreatment system was shown in Additional file 6: Figure S6.
The pressure tube containing solvent was preheated for about $5 \mathrm{~min}$ to reach $90^{\circ} \mathrm{C}$ (measured by an external thermometer) and $33 \mu \mathrm{L}$ of $98 \mathrm{wt} \% \mathrm{H}_{2} \mathrm{SO}_{4}$ was added and the solution mixed for $30 \mathrm{~s}$. Thereafter, $0.538 \mathrm{~g}$ of bagasse (0.5 g of dry biomass) or $0.5 \mathrm{~g}$ of MCC was transferred into the pressure tube. The ratio of total liquid to sugarcane bagasse (dry weight) was 10:1 (w/w) $(\mathrm{AC} / \mathrm{AG}$ solvents to bagasse $=9.8: 1, \mathrm{w} / \mathrm{w})$. After $30 \mathrm{~min}$ of reaction time, $5 \mathrm{~mL}$ of water was added to the pressure tube and the mixture was thoroughly mixed. The mixture was filtered (Whatman 541 filter paper) to collect the pretreated biomass. The filtrate was collected and frozen for further analysis. The pretreated bagasse was washed with $200 \mathrm{~mL}$ distilled water $(2 \times 100 \mathrm{~mL} /$ wash $)$. The washed pretreated bagasse was further washed with $50 \mathrm{mM} \mathrm{NaOH}$ solution $(2 \times 20 \mathrm{~mL} /$ wash $)$ followed by further water wash $(2 \times 100 \mathrm{~mL} /$ wash $)$. The washed pretreated bagasse was collected. Pretreated MCC was only washed with water $(2 \times 100 \mathrm{~mL} /$ wash $)$. Half of the filtered biomass was freeze-dried for moisture analysis and stored for further analyses (SEM, XRD and biomass compositional analysis), while the other half of the filtered biomass was stored at $4^{\circ} \mathrm{C}$ for enzymatic hydrolysis. All the pretreatments were conducted in triplicate.

\section{Enzymatic hydrolysis}

Enzymatic hydrolysis was carried out in a $20 \mathrm{~mL}$ glass vial containing $5 \mathrm{~g}$ solution in which half of the pretreated and washed biomass (equivalent to $0.130-0.250 \mathrm{~g}$ dry biomass due to the difference in biomass yields) was added. The reaction solution contained $0.05 \mathrm{M}$ citrate buffer to maintain $\mathrm{pH} 4.8$ and 0.02 wt\% sodium azide to prevent the growth of microorganisms. The dosage of Accellerase for enzymatic hydrolysis was $0.025 \mathrm{~mL}$ Accellerase/g solution (45-50 FPU/g glucan due to the difference in glucan recovery). The reaction was carried out at $50^{\circ} \mathrm{C}$ for $72 \mathrm{~h}$ in a rotary incubator (Ratek OM 11 Orbital Mixer, Australia) with shaking speed of $150 \mathrm{rpm}$. After $72 \mathrm{~h}$ enzymatic hydrolysis, $0.5 \mathrm{~mL}$ of solution was withdrawn and then centrifuged at 9,000 $\mathrm{g}$ for $5 \mathrm{~min}$. $0.1 \mathrm{~mL}$ supernatant was diluted 10 times by de-ionized water. The diluted sample was filtered through $0.22 \mu \mathrm{m}$ disk filter prior to sugar analysis by a high performance liquid chromatography (HPLC) system. All the enzymatic hydrolysis experiments were conducted in triplicate.

\section{Characterisation of biomass samples}

Biomass samples were characterised by FTIR, SEM, XRD and compositional analysis. FTIR spectra of the samples were recorded between $4000 \mathrm{~cm}^{-1}$ and $500 \mathrm{~cm}^{-1}$ using a Thermo Nicolet Nexus 870 system (Thermo Nicolet, USA) with the processing software Omnic 7.3. SEM was used to record the surface morphological features of bagasse before and after pretreatment. The samples 
were coated with gold using a Leica EMS CD 005 system prior to analysis by FEI scanning electron microscope (Quanta 200 3D, USA).

The X-ray diffractometer (PANalytical, Netherlands) with $\mathrm{Cu} \mathrm{K}$ radiation $(\lambda=1.5418 \mathrm{~nm})$ was operated at a voltage of $40 \mathrm{kV}$ and a current of $40 \mathrm{~mA}$. The $2 \theta$ range was from $4^{\circ}$ to $40^{\circ}$ in steps of $0.033^{\circ}$ at a rate of $2.6^{\circ} / \mathrm{min}$. Crystallinity index (CrI) was calculated by:

$$
\mathrm{CrI}=\frac{I_{002}-I_{a m}}{I_{002}}
$$

where $I_{002}$ at $2 \theta=21.5-23.0^{\circ}$ is the total intensity of crystalline and amorphous components, $I_{a m}$ at $2 \theta=17-$ $19^{\circ}$ is the "valley" intensity of amorphous cellulose, hemicellulose and lignin considering the shift of these peaks after pretreatment [10]. After XRD analysis, the biomass was recovered for compositional analysis using a modified method, which was based on a standard method developed by the NREL [51], however, instead of using $300 \mathrm{mg}$ of biomass sample, $100 \mathrm{mg}$ of each sample was used for analysis (due to the limited size of samples). The acid and water amounts added were also reduced proportionately. All the other operational procedures were the same as the standard method.

To better understand the effect of pretreatment on biomass properties, dye adsorption studies to reveal surface area change of MCC after pretreatment were conducted. A stock CR solution of $600 \mathrm{mg} / \mathrm{L}$ was prepared and the $\mathrm{pH}$ was adjusted to 7.0 by adding dilute $\mathrm{NaOH}$ or $\mathrm{HCl}$ solution Dye adsorption experiment was conducted at room temperature $\left(24^{\circ} \mathrm{C}\right)$ in a $20 \mathrm{~mL}$ glass bottle with $10 \mathrm{~mL} \mathrm{CR}$ solution $(200 \mathrm{mg} / \mathrm{L})$ and $5 \mathrm{~g} / \mathrm{L}$ pretreated MCC. Adsorption was carried out at $24^{\circ} \mathrm{C}$ for $20 \mathrm{~h}$ in a rotary incubator (Ratek OM 11 Orbital Mixer, Australia) with shaking speed of $150 \mathrm{rpm}$. After $20 \mathrm{~h}$ adsorption, the optical density of the CR solution was monitored at $497 \mathrm{~nm}$ and the concentration was calculated using a standard calibration curve.

\section{HPLC analysis}

A HPLC system with a Bio-Rad Aminex HPX-87H column and Waters refractive index detector was used to detect and quantify sugar derivatives such as 5-hydroxymethylfurfural (HMF) and furfural in the pretreatment solution. The mobile phase was $5 \mathrm{mM} \mathrm{H}_{2} \mathrm{SO}_{4}$ at a flow rate of $0.6 \mathrm{~mL} / \mathrm{min}$. The column temperature was $65^{\circ} \mathrm{C}$. A Phenominex RPM monosaccharide column was used to determine the sugars generated from pretreatment solutions and enzymatic hydrolysis. The pretreatment solution was neutralised with $\mathrm{CaCO}_{3}$ prior to sugar and solvent analysis. The column temperature was $85^{\circ} \mathrm{C}$ and the mobile phase was water at a flow rate of $0.5 \mathrm{~mL} / \mathrm{min}$.

\section{Calculations}

Biomass yield was calculated based on the following equation:

$$
\begin{aligned}
& \text { Biomass yield } \\
& =\frac{\text { Dry biomass weight after pretreatment } \times 100 \%}{\text { Dry weight of untreated biomass }}
\end{aligned}
$$

For MCC, the biomass yield was the same as cellulose yield.

Component (glucan, xylan and lignin) recovery in pretreated bagasse was calculated as follows:

$$
\begin{aligned}
& \text { Component recovery } \\
& =\frac{\text { Component content in pretreated biomass } \times \text { biomass yield } \times 100 \%}{\text { Total component in untreated bagasse }}
\end{aligned}
$$

Glucose enzymatic hydrolysis yield of pretreated biomass was calculated based on the following equation:

$$
\begin{aligned}
& \text { Glucose enzymatic hydrolosis yield } \\
& =\frac{\text { Total glucose in enzymatic } \times 162 / 180 \times 100 \%}{\text { Total glucan in untreated biomass }}
\end{aligned}
$$

where 162 is the molecular weight (MW) of glucose unit in glucan and 180 is the MW of glucose.

Glucan enzymatic digestibility of pretreated biomass was calculated based on the following equation:

$$
\begin{aligned}
& \begin{array}{l}
\text { Glucan enzymatic digestability } \\
=\frac{\text { Glucose enzymatic hydrolosis yeild } \times 100 \%}{\text { Glucan recovery }}
\end{array}
\end{aligned}
$$

The yields of glucose (HMF, xylose and furfural) detected in pretreatment solution on total glucan (xylan) in untreated biomass was calculated based on the following equations:

$$
\begin{aligned}
& \text { Glucose yield } \\
& =\frac{\text { Total glucose in pretreatment solution } \times 162 / 180 \times 100 \%}{\text { Total glucan in untreated biomass }}
\end{aligned}
$$

where 162 is the MW of glucose unit in glucan and 180 is the MW of glucose.

$$
\begin{aligned}
& \text { Xylose yield } \\
& =\frac{\text { Total xylose in pretreatment solution } \times 132 / 150 \times 100 \%}{\text { Total xylan in untreated biomass }}
\end{aligned}
$$


where 132 is the MW of xylose unit in xylan and 150 is the MW of xylose.

$$
\begin{aligned}
& \text { HMF yield } \\
& \qquad=\frac{\text { Total HMF in pretreatment solution } \times 162 / 126 \times 100 \%}{\text { Total glucan in untreated biomass }}
\end{aligned}
$$

where 162 is the MW of glucose unit in glucan and 126 is the MW of HMF.

$$
\begin{aligned}
& \text { Furfural yield } \\
& \qquad=\frac{\text { Total furfural in pretreatment solution } \times 132 / 96 \times 100 \%}{\text { Total xylan and arabinan in untreated biomass }}
\end{aligned}
$$

where 132 is the MW of xylose unit in xylan and 96 is the MW of furfural.

The extent of GC decomposition (the yield of glycerol) after pretreatment by GC alone was calculated based on the following equation:

$$
\begin{aligned}
& \text { GC decomposition } \\
& =\frac{\text { Total glycerol in pretreatment solution } \times 118 / 92 \times 100 \%}{\text { Total GC in initial pretreatment solution }}
\end{aligned}
$$

where 118 is the MW of GC and 92 is the MW of glycerol.

CR adsorption capacity (mg/g MCC) was calculated based on the follow equation:

$$
\begin{aligned}
& \text { Dye adsorption capacity } \\
& =\frac{\text { Total dye-free dye in solution after adsorption }}{\text { Total MCC in solution }}
\end{aligned}
$$

All the data shown in this study are the means of triplicate experiments with standard deviation also shown.

\section{Additional files}

Additional file 1: Figure S1. XRD spectra of representative samples.

Additional file 2: Figure S2. SEM images of bagasse samples

pretreated by (a) GC, (b) EC, (c) glycerol and (d) EG.

Additional file 3: Figure S3. Glucose yield in hydrolysed pretreatment solution after MCC pretreatment (Pretreatment solution was diluted to a water content of $75 \mathrm{wt} \%$ and incubated in a sealed pressure tube for $30 \mathrm{~min}$ at $\left.130^{\circ} \mathrm{C}\right)$.

Additional file 4: Figure S4. SEM images of (a) untreated MCC, MCC samples pretreated by (b) EC, (c) GC, (d) EG and (e) glycerol.

Additional file 5: Figure S5. Langmuir isotherm of CR adsorption on MCC. Additional file 6: Figure S6. Picture of the reactor system.

\section{Abbreviations}

AC: Alkylene carbonate; AG: Alkylene glycol; CR: Congo red; EC: Ethylene carbonate; EG: Ethylene glycol; $\varepsilon$ : Static relative dielectric constant; FTIR: Fourier transform infrared spectroscopy; GC: Glycerol carbonate; HMF: 5-hydroxymethylfurfural; HPLC: High performance liquid chromatography; MW: Molecular weight; PC: Propylene carbonate;

PG: Propylene glycol; SEM: Scanning electron microscopy.

\section{Competing interests}

The authors declare that they have no competing interests.

\section{Authors' contributions}

ZZ designed and conducted the experiments, analysed and discussed the results, and prepared the manuscript. DR, WD and IO participated in discussion of the results and provided suggestions on preparation and revision of the manuscript. All authors read and approved the final manuscript.

\section{Acknowledgements}

The authors gratefully acknowledge the financial contribution and support provided by the Australian Government Sugar Research and Development Corporation (SRDC) and Syngenta Biotechnology Inc., USA.

Received: 24 June 2013 Accepted: 10 October 2013

Published: 24 October 2013

\section{References}

1. Hendriks A, Zeeman G: Pretreatments to enhance the digestibility of lignocellulosic biomass. Bioresour Technol 2009, 100:10-18.

2. Mosier N, Wyman C, Dale B, Elander R, Lee YY, Holtzapple M, Ladisch M: Features of promising technologies for pretreatment of lignocellulosic biomass. Bioresour Technol 2005, 96:673-686.

3. Zhu JY, Pan XJ, Zalesny RS: Pretreatment of woody biomass for biofuel production: energy efficiency, technologies, and recalcitrance. App/ Microbiol Biotechnol 2010, 87:847-857.

4. Camacho F, GonzalezTello P, Jurado E, Robles A: Microcrystalline-cellulose hydrolysis with concentrated sulphuric acid. J Chem Technol Biotechnol 1996, 67:350-356.

5. Iranmahboob J, Nadim F, Monemi S: Optimizing acid-hydrolysis: a critical step for production of ethanol from mixed wood chips. Biomass Bioenerg 2002, 22:401-404.

6. Huang YB, Fu Y: Hydrolysis of cellulose to glucose by solid acid catalysts. Green Chem 2013, 15:1095-1111.

7. Kuo CH, Lee CK: Enhancement of enzymatic saccharification of cellulose by cellulose dissolution pretreatments. Carbohyd Polym 2009, 77:41-46.

8. Zhang Z, O'Hara IM, Doherty WOS: Effects of $\mathrm{pH}$ on pretreatment of sugarcane bagasse using aqueous imidazolium ionic liquids. Green Chem 2013, 15:431-438

9. Hou XD, Li N, Zong MH: Renewable bio ionic liquids-water mixturesmediated selective removal of lignin from rice straw: Visualization of changes in composition and cell wall structure. Biotechnol Bioeng 2013, 110:1895-1902.

10. Zhang Z, O'Hara IM, Rackemann DW, Doherty WOS: Low temperature pretreatment of sugarcane bagasse at atmospheric pressure using mixtures of ethylene carbonate and ethylene glycol. Green Chem 2013 15:255-264.

11. Sonnati MO, Amigoni S, de Givenchy EP T, Darmanin T, Choulet O, Guittard F: Glycerol carbonate as a versatile building block for tomorrow: synthesis, reactivity, properties and applications. Green Chem 2013, 15:283-306.

12. International Programme on Chemical Safety (IPCS): Ethylene glycol. Poisons Inform Monograph 2001. PIM 227, http://www.inchem.org/ documents/pims/chemical/pim227.htm, accessed on March 28, 2013.

13. Chernyak Y: Dielectric constant, dipole moment, and solubility parameters of some cyclic acid esters. J Chem Eng Data 2006, 51:416-418.

14. Aresta M, Dibenedetto A, Nocito F, Pastore C: A study on the carboxylation of glycerol to glycerol carbonate with carbon dioxide: The role of the catalyst, solvent and reaction conditions. J Mol Catal A-Chem 2006, 257:149-153.

15. George J, Patel Y, Pillai SM, Munshi P: Methanol assisted selective formation of 1,2-glycerol carbonate from glycerol and carbon dioxide using $\left(\mathrm{Bu}_{2} \mathrm{SnO}\right)-\mathrm{Bu}-\mathrm{n}$ as a catalyst. J Mol Catal A-Chem 2009, 304:1-7.

16. Hammond C, Lopez-Sanchez JA, Ab Rahim MH, Dimitratos N, Jenkins RL, Carley AF, He Q, Kiely CJ, Knight DW, Hutchings GJ: Synthesis of glycerol carbonate from glycerol and urea with gold-based catalysts. Dalton $T$ 2011, 40:3927-3937. 
17. Wang LG, Ma YB, Wang Y, Liu SM, Deng YQ: Efficient synthesis of glycerol carbonate from glycerol and urea with lanthanum oxide as a solid base catalyst. Catal Commun 2011, 12:1458-1462

18. Takagaki A, Iwatani K, Nishimura S, Ebitani K: Synthesis of glycerol carbonate from glycerol and dialkyl carbonates using hydrotalcite as a reusable heterogeneous base catalyst. Green Chem 2010, 12:578-581.

19. Malyaadri M, Jagadeeswaraiah K, Prasad PSS, Lingaiah N: Synthesis of glycerol carbonate by transesterification of glycerol with dimethyl carbonate over Mg/Al/Zr catalysts. Appl Catal A-Gen 2011, 401:153-157.

20. Simanjuntak FSH, Kim TK, Lee SD, Ahn BS, Kim HS, Lee H: CaO-catalyzed synthesis of glycerol carbonate from glycerol and dimethyl carbonate: Isolation and characterization of an active Ca species. App/ Catal A-Gen 2011, 401:220-225.

21. Tudorache M, Protesescu L, Coman S, Parvulescu VI: Efficient bioconversion of glycerol to glycerol carbonate catalyzed by lipase extracted from Aspergillus niger. Green Chem 2012, 14:478-482.

22. Kim SC, Kim YH, Lee H, Yoon DY, Song BK: Lipase-catalyzed synthesis of glycerol carbonate from renewable glycerol and dimethyl carbonate through transesterification. J Mol Catal B-Enzym 2007, 49:75-78.

23. Song Q, Wang F, Cai J, Wang Y, Zhang J, Yu W, Xu J: Lignin depolymerization (LDP) in alcohol over nickelbased catalysts via a fragmentation-hydrogenolysis process. Energ Environ Sci 2013, 6:994-1007.

24. Carpita NC, Gibeaut DM: Structural models of primary-cell walls in flowering plants - consistency of molecular-structure with the physicalproperties of the walls during growth. Plant J 1993, 3:1-30.

25. liyama K, Lam TBT, Stone BA: Covalent cross-links in the cell-wall. Plant Physiol 1994, 104:315-320.

26. Liu L, Sun JS, Li M, Wang SH, Pei HS, Zhang JS: Enhanced enzymatic hydrolysis and structural features of corn stover by $\mathrm{FeCl}_{3}$ pretreatment. Bioresour Technol 2009, 100:5853-5858.

27. Guo GL, Chen WH, Chen WH, Men LC, Hwang WS: Characterization of dilute acid pretreatment of silvergrass for ethanol production. Bioresour Technol 2008, 99:6046-6053.

28. Zhao XB, Wang L, Liu DH: Peracetic acid pretreatment of sugarcane bagasse for enzymatic hydrolysis: a continued work. J Chem Technol Biotechnol 2008, 83:950-956.

29. Sun XF, Xu F, Sun RC, Fowler P, Baird MS: Characteristics of degraded cellulose obtained from steam-exploded wheat straw. Carbohyd Res 2005, 340:97-106.

30. Li CL, Knierim B, Manisseri C, Arora R, Scheller HV, Auer M, Vogel KP, Simmons BA, Singh S: Comparison of dilute acid and ionic liquid pretreatment of switchgrass: Biomass recalcitrance, delignification and enzymatic saccharification. Bioresour Technol 2010, 101:4900-4906.

31. Zhang Z, O'Hara IM, Doherty WOS: Pretreatment of sugarcane bagasse by acid-catalysed process in aqueous ionic liquid solutions. Bioresour Technol 2012, 120:149-156.

32. Sinitsyn AP, Gusakov AV, Vlasenko EY: Effect of structural and physicochemical features of cellulosic substrates on the efficiency of enzymatic hydrolysis. Appl Biochem Biotech 1991, 30:43-60.

33. Arantes V, Saddler JN: Cellulose accessibility limits the effectiveness of minimum cellulase loading on the efficient hydrolysis of pretreated lignocellulosic substrates. Biotechnol Biofuel 2011, 4:3.

34. Rollin JA, Zhu ZG, Sathitsuksanoh N, Zhang YHP: Increasing cellulose accessibility is more important than removing lignin: a comparison of cellulose solvent-based lignocellulose fractionation and soaking in aqueous ammonia. Biotechnol Bioeng 2011, 108:22-30.

35. Liu JA, Takada R, Karita S, Watanabe T, Honda Y, Watanabe T: Microwaveassisted pretreatment of recalcitrant softwood in aqueous glycerol. Bioresour Technol 2010, 101:9355-9360.

36. Pan XJ, Xie D, Yu RW, Saddler JN: The bioconversion of mountain pine beetle-killed lodgepole pine to fuel ethanol using the organosolv process. Biotechnol Bioeng 2008, 101:39-48.

37. Park N, Kim HY, Koo BW, Yeo H, Choi IG: Organosolv pretreatment with various catalysts for enhancing enzymatic hydrolysis of pitch pine (Pinus rigida). Bioresour Technol 2010, 101:7046-7053.

38. Teramoto $Y$, Lee SH, Endo T: Cost reduction and feedstock diversity for sulfuric acid-free ethanol cooking of lignocellulosic biomass as a pretreatment to enzymatic saccharification. Bioresour Technol 2009, 100:4783-4789.

39. Jiménez L, de la Torre MJ, Maestre F, Ferrer JL, Pérez I: Organosolv pulping of wheat straw by use of phenol. Bioresour Technol 1997, 60:199-205.
40. Yamada T, Ono H: Rapid liquefaction of lignocellulosic waste by using ethylene carbonate. Bioresour Technol 1999, 70:61-67.

41. Brosse N, El Hage R, Sannigrahi P, Ragauskas A: Dilute sulfuric acid and ethanol organosolv pretreatment of Miscanthus x Giganteus. Cell Chem Technol 2010, 44:71-78.

42. Qin L, Liu ZH, Li BZ, Dale BE, Yuan YJ: Mass balance and transformation of corn stover by pretreatment with different dilute organic acids. Bioresour Technol 2012, 112:319-326.

43. Zhang Z, Wong HH, Albertson PL, Doherty WOS, O'Hara IM: Laboratory and pilot scale pretreatment of sugarcane bagasse by acidified aqueous glycerol solutions. Bioresour Technol 2013, 138:14-21.

44. Weingarten R, Cho J, Conner WC, Huber GW: Kinetics of furfural production by dehydration of xylose in a biphasic reactor with microwave heating. Green Chem 2010, 12:1423-1429.

45. Shen J, Kaur I, Baktash MM, He ZB, Ni YH: A combined process of activated carbon adsorption, ion exchange resin treatment and membrane concentration for recovery of dissolved organics in pre-hydrolysis liquor of the kraft-based dissolving pulp production process. Bioresour Technol 2013, 127:59-65.

46. Huntsman Corporation: JEFFSOL ${ }^{\circledR}$ glycerol carbonate. Tech Bull. http://www. huntsman.com/portal/page/portal/performance_products/Media\%20Library/ global/files/jeffsol_glycerine_carbonate.pdf, accessed on March 28, 2013.

47. Shankar PN, Kumar M: Experimental-determination of the kinematic viscosity of glycerol water mixtures. P Roy Soc Lond a Mat 1994, 444:573-581.

48. Zhang ZY, Moghaddam L, O'Hara IM, Doherty WOS: Congo Red adsorption by ball-milled sugarcane bagasse. Chem Eng J 2011, 178:122-128.

49. Thring RW, Chornet E, Overend RP: Recovery of a solvolytic lignin - effects of spent liquor acid volume ratio, acid concentration and temperature. Biomass 1990, 23:289-305.

50. Adney B, Baker J: Measurement of Cellulase Activities. Measurement of Cellulase Activities. Battelle, USA: National Renewable Energy Laboratory; 2008.

51. Sluiter A, Hames B, Ruiz R, Scarlata C, Sluiter J, Templeton D, Crocker D: Determination of structural carbohydrates and lignin in biomass. Battelle, USA: National Renewable Energy Laboratory; 2008.

doi:10.1186/1754-6834-6-153

Cite this article as: Zhang et al:: Glycerol carbonate as green solvent for pretreatment of sugarcane bagasse. Biotechnology for Biofuels 2013 6:153.

\section{Submit your next manuscript to BioMed Central and take full advantage of:}

- Convenient online submission

- Thorough peer review

- No space constraints or color figure charges

- Immediate publication on acceptance

- Inclusion in PubMed, CAS, Scopus and Google Scholar

- Research which is freely available for redistribution 